Published in final edited form as:

Appetite. 2013 June ; 65: 178-184. doi:10.1016/j.appet.2013.01.018.

\title{
Food insecurity with past experience of restrained eating is a recipe for increased gestational weight gain
}

\author{
Barbara Laraia $^{a}$, Elissa Epel ${ }^{b}$, and Anna Maria Siega-Riz ${ }^{c}$ \\ Barbara Laraia: blaraia@berkeley.edu; Elissa Epel: eepel@Ippi.ucsf.edu; Anna Maria Siega-Riz: am_siegariz@unc.edu \\ aAssociate Professor, Division of Community Health \& Human Development, School of Public \\ Health, University of California Berkeley, 207-B University Hall, Berkeley, CA, Tele: \\ 510-643-7896, Fax: 510-643-6426 \\ ${ }^{b}$ Associate Professor, Department of Psychiatry, University of California, Campus Box 0844, 3333 \\ California St, Suite 465, San Francisco, CA 94118, Tele: 415-476-7648, Fax: 415-476-7744
}

'Professor, Departments of Epidemiology and Nutrition, Associate Dean for Academic Affairs, School of Public Health, University of North Carolina at Chapel Hill, 2105-A McGavranGreenberg, Campus Box 7435, Chapel Hill, NC 27599-7435, Tele: 919-962-8410, Fax: 919-966-9159

\begin{abstract}
Food insecurity is linked to higher weight gain in pregnancy, as is dietary restraint. We hypothesized that pregnant women exposed to marginal food insecurity, and who reported dietary restraint before pregnancy, will paradoxically show the greatest weight gain. Weight outcomes were defined as total kilograms, observed-to-recommended weight gain ratio, and categorized as adequate, inadequate or excessive weight gain based on 2009 Institute of Medicine guidelines. A likelihood ratio test assessed the interaction between marginal food insecurity and dietary restraint and found significant. Adjusted multivariate regression and multinomial logistic models were used to estimate weight gain outcomes. In adjusted models stratified by dietary restraint, marginal insecurity and low restraint was significantly associated with lower weight gain and weight gain ratio compared to food secure and low restraint. Conversely, marginal insecurity and high restraint was significantly associated with higher weight gain and weight gain ratio compared to food secure and high restraint. Marginal insecurity with high restraint was significantly associated with excessive weight gain. Models were consistent when restricted to low-income women and fullterm deliveries. In the presence of marginal food insecurity, women who struggle with weight and dieting issues may be at risk for excessive weight gain.
\end{abstract}

\section{Keywords}

food insecurity; dietary restraint; weight gain; dieting; disordered eating; pregnancy

\section{(C) 2013 Published by Elsevier Ltd.}

Correspondence to: Barbara Laraia, blaraia@berkeley . edu.

Publisher's Disclaimer: This is a PDF file of an unedited manuscript that has been accepted for publication. As a service to our customers we are providing this early version of the manuscript. The manuscript will undergo copyediting, typesetting, and review of the resulting proof before it is published in its final citable form. Please note that during the production process errors may be discovered which could affect the content, and all legal disclaimers that apply to the journal pertain. 


\section{INTRODUCTION}

Household food insecurity is a social ill and public health concern that affects the most vulnerable of our population - households with low-income, people of color and single female headed households with children. Household food insecurity, defined as "whenever the availability of nutritionally adequate and safe food, or the ability to acquire acceptable foods in socially acceptable ways, is limited or uncertain" (Anderson, 1990), is simultaneously an economic indicator measuring household resource constraints, a nutritional indicator measuring access to food, and a psychological stressor.

Consistent findings across a number of studies show that members of households suffering from food insecurity are more likely to incur compromised psychosocial functioning (Kleinman et al., 1998; Olson, 1999; Vozoris \& Tarasuk, 2003), worse mental health (Casey et al., 2004; Gundersen, Weinreb, Wehler, \& Hosmer, 2003; Laraia, Siega-Riz, Gundersen, \& Dole, 2006; Stuff et al., 2004), and depression (Che \& Chen, 2001; Vozoris \& Tarasuk, 2003). Food insecurity has been associated with disordered eating patterns as measured by the Stanford Eating Disorder Questionnaire used to measure the extent of binge eating, which was hypothesized to predispose women to obesity (Kendall, Olson, \& Frongillo, 1996). This may be spurred on by both a desire for energy dense, high fat, refined carbohydrate foods and because food availability may be cyclical—more available closer to the beginning of the month and scarce toward the end of the month. Several studies have shown that families exposed to food insecurity experience this cyclic nature of food availability (Hamelin, Beaudry, \& Habicht, 2002; Seligman, Jacobs, Lopez, Tschann, \& Fernandez, 2012; Taren, Clark, Chernesky, \& Quirk, 1990) and this exposure is hypothesized to disrupt metabolism. Taren et al. (1990) showed that in low-income households, the number of servings per week decreased in the last week of the month, especially in families with young children. Kendall et al., (1996) found that women from food insecure households consumed significantly less fruits and vegetables but not high carbohydrate foods such as fruit juice or potatoes. Additionally, dairy, meat, grains, fruits and vegetables were all significantly less available in participants' homes. Seligman et al. (2012) showed that food ran out at the end of the month and hypoglycemia among adults with diabetes increased at the same time. When food is scarce, low-income families depend on inexpensive and calorically dense foods of low nutritional value that are associated with weight gain (Drewnowski \& Specter, 2004). The combination of stress, poor eating behaviors and overeating energy dense, highly palatable foods is hypothesized to lead to weight gain over time.

Household food insecurity has been associated with higher BMI (Olson, 1999) and a greater risk of overweight (Townsend, Peerson, Love, Achterberg, \& Murphy, 2001) and obesity (Adams, Grummer-Strawn, \& Chavez, 2003) among women in cross-sectional studies. Household food insecurity has been inconsistently associated with weight gain. Among nonpregnant women, Wilde and Peterman (2006) found that a higher proportion of women from food insecure households gained more than 10 pounds over a 12 month period compared to women from food secure households. However, Jones and Frongillo (2007) found no association between food insecurity and subsequent weight gain among women (Jones \& Frongillo, 2007). We previously found that on average, pregnant women from food insecure households gained almost two kilograms more during pregnancy and had a higher ratio of observed to recommended weight gain compared to pregnant women from food secure homes (Laraia, Siega-Riz, \& Gundersen, 2010). Given that the insufficient food serves as a potent psychological stressor, and any level of household food insecurity, either marginal food security or food insecurity, is associated strongly with psychological perceived stress (Laraia et al., 2006), we label any exposure to concern about enough food as marginal food insecurity to emphasize its role as a stressor. 
Dietary restraint, defined as the extent to which a person thinks about their diet and weight and tries to restrict dietary intake, and measured by the revised restraint scale, a scale that tends to predict unsuccessful dieting (Conway, Reddy, \& Davies, 1999) has been associated with higher gestational weight gain and a higher observed to recommended weight gain ratio during pregnancy (Mumford, Siega-Riz, Herring, \& Evenson, 2008). Dietary restraint, like food insecurity, has been linked to bouts of restrictive eating followed by overeating during pregnancy, particularly in response to stress (Conway et al., 1999). The combination of high restraint and high perceived stress may both stimulate the reward center and lead to excessive intake of comfort food-e.g., non-nutritive calorically dense foods (Adam \& Epel, 2007). During pregnancy, stress has been found to be associated with poor dietary intake; pregnant women who were more fatigued, stressed and anxious were found to have higher caloric and lower micronutrient intake during pregnancy (Hurley, Caulfield, Sacco, Costigan, \& Dipietro, 2005).

Based on the findings that both the stress of food insecurity and restrained eating are linked to dysregulated eating, that they are both associated with higher gestational weight gain, and that dietary restraint and food insecurity may work together to promote reward-based overeating, we were interested in testing whether there may be additive effects of being food insecure and exhibiting a high level of dietary restraint on gestational weight gain. Specifically we hypothesized that women who are exposed to any level of household food insecurity and score high on restrained eating would have the greatest gestational weight gain, independent of prepregnancy body mass index.

\section{MATERIALS AND METHODS}

\section{Study Sample}

This study used data from the Pregnancy, Infection, and Nutrition (PIN3) cohort, a prospective study that examined the influence of several socio-behavioral and medical factors on the risk of preterm birth. A total of 2,006 pregnant women were recruited from January 1, 2001 to June 30, 2005 though the University of North Carolina Hospitals residents and private physician obstetrics clinics before 20 weeks' gestation. Women who were younger than age 16, non-English-speaking, not planning to continue care or deliver at the study site, or carrying multiple gestations, were not eligible to participate. Protocols for data collection in this cohort have been previously reported (Mumford et al., 2008) but briefly, information on pre- and perinatal factors including sociodemographic characteristics and medical history were assessed by interviews, self-administered questionnaires, and information from medical records. Medical charts were abstracted for all women in the cohort to collect data on reproductive history, weight gain, pregnancy complications, and labor and delivery events. The procedures followed for this study were in accordance with the ethical standards of the Institutional Review Board of the University of North Carolina School of Medicine.

Of the 2,006 women recruited, 1,773 had information on pregravid height, weight, and weight gain. Women were excluded from these analyses if they had a stillbirth $(\mathrm{n}=13)$, incomplete information on household food security $(n=213)$, or lacked information on the Revised Restraint Scale (RRS). The RRS was added to the study four months after recruitment began, therefore, those recruited prior to April 24, 2001 did not have information on the restrained eating scale $(\mathrm{n}=506)$. This resulted in an analysis sample of 1,041 women. Pregnant women excluded for any reason had a lower mean age ( 26.8 vs. 29.2 years), mean education ( 13.6 vs. 15.6 years), mean income ( $252 \%$ vs. $408 \%$ of the federal income/poverty ratio), respectively, and a higher proportion were black ( $20 \%$ black vs. $7 \%$ white). 


\section{Marginal Food Insecurity}

To calculate the official food insecurity rates in the U.S., a series of 18 questions were posed in the Core Food Security Module (CFSM) for families with children (Bickel, Nord, Price, Hamilton, \& Cook, 2000). Each question was designed to capture some aspect of food insecurity and, for some questions, the frequency with which it manifests itself. Questions were asked about the household's experience over the past 12 months. Examples included, "I worried whether our food would run out before we got money to buy more," (the least severe question); "Did you or the other adults in your household ever cut the size of your meals or skip meals because there wasn't enough money for food;" "Were you ever hungry but did not eat because you couldn't afford enough food;" and "Did a child in the household ever not eat for a full day because you couldn't afford enough food" (the most severe question). We first created a categorical variable indicating a household as (a) food secure if the respondent responded "no" to all of the questions, and (b) marginally secure if one or two questions were answered in the affirmative, and (c) food insecure if three or more questions were answered in the affirmative (Bickel et al., 2000). We tested if socioeconomic (SES) characteristics - age, race, education, income and marital status—and weight outcomes differed among these groups. Socioeconomic characteristics and weight related outcomes did not differ between women from marginally food secure and food insecure households. SES characteristics, BMI and observe-to-recommended weight gain were significantly different from women from food secure households. Therefore, we collapsed the marginally food secure and food insecure categories and created a dichotomous indicator variable called marginal food insecurity if the respondent responded affirmatively to one or more questions (Ziliak \& Gundersen, 2009; Laraia et al., 2006).

\section{Dietary Restraint}

Restrained eating measured history of dieting and weight fluctuations using the Revised Restraint Scale (RRS) (Herman \& Mack, 1975; Herman, 1980). The RRS is a 10-item scale with four to five possible responses which measures history of dieting and concern about eating too much food. It has been strongly linked to dysregulated eating patterns (Herman \& Mack, 1975; Herman, 1980). An overall score for Restrained Eating was calculated by summing across all items. The items assess frequency of dieting, eating behaviors, emotional eating, awareness of food choices, and amount of time spent concerned about food, weight fluctuations and ideal weight. We used the modified RRS scale by Conway and colleagues (Conway et al., 1999) which focused on the period prior to pregnancy, so as not to include weight and appetite changes during pregnancy. The overall Cronbach's alpha for the 10 items was 0.77. Score for two subscales (Ruderman, 1983)—dieters and weight cyclers-were also created as we sought to understand if one of the subscales may have a stronger association with marginal food insecurity and weight gain, or if together they influence weight gain. The dieting subscale used six questions about frequency of dieting, lifestyle changes after a weight fluctuation of $5 \mathrm{lbs}$, public and private eating behaviors, feelings of guilt after overeating, consciousness of food choices, and amount of time spent concerned about food. The Cronbach's alpha was 0.74 . The weight cycler subscale was calculated using four questions that pertained to typical weight fluctuation in the nonpregnancy state, maximum weight ever lost within one month, maximum weight gained within one week, number of pounds over desired weight at maximum weight. The Cronbach's alpha was 0.54 . As there are no established cutpoints for the RRS, we previously used sample medians for analysis with this sample (Mumford et al., 2008) consistent with the original research by Conway et al. (1999). Restrained eating was dichotomized at the median (median $=11)$ to identify high vs. low restraint groups. 


\section{Heath outcomes}

At the second telephone interview conducted between 26 to 31 weeks' gestation, information on health behaviors, household food security status and food coping behaviors and previous as well as current medical history was solicited. Self-reported pre-pregnancy weight and measured height at the first prenatal visit, checked for biological plausibility, and were used to construct pregravid body mass index (BMI) $\mathrm{kg} / \mathrm{m} 2$. The validity of selfreported weight by pregnant women has been examined previously and has been shown to be good if collected early in pregnancy and examined for biologically implausible values (Stevens-Simon, Roghmann, \& McAnarney, 1992; Yu \& Nagey, 1992). For 4\% (n=42) of the analysis sample, an imputed weight was used in lieu of the self-reported measure only when it was missing or considered biologically implausible. This imputed weight was calculated using the measured weight at the first prenatal visit (if taken prior to 16 weeks) minus the recommended amount of weight to be gained in the first and second trimesters as defined by the Institute of Medicine (Rasmussen \& Yaktine, 2009). If the first weight measurement was after 15 weeks of gestation, a pre-pregnancy weight could not be imputed. This methodology has been previously used with our group on other analyses (Siega-Riz, Adair, \& Hobel, 1994, 1996).

Gestational weight gain was calculated as the difference between each woman's pregravid weight and her weight measured at the last prenatal visit near the time of delivery. The average week gestation at the time of the last visit and weight measure was $38.1(\mathrm{sd}=2.4)$; 93.6\% had their last weight within two weeks of delivery. All but three women had their last visit during the third trimester, two of which delivered preterm. In this analysis gestational weight gain was represented in three ways. First, weight gain was expressed as a continuous variable measured in kilograms. Second, an observed to recommended gestational weight gain ratio was calculated according to pregravid BMI status, and was a ratio of observed total weight gain over expected weight gain up until the last prenatal visit using the weight gain recommendations from the 2009 IOM report as previously described (Deierlein, SiegaRiz, \& Herring, 2008; Mumford et al., 2008; Rasmussen \& Yaktine, 2009). Third, a categorical variable classifying women in to inadequate, adequate and excessive was created using previously established cut points (Deierlein et al., 2008; Mumford et al., 2008). For example, it is recommended that an overweight woman gain between 7.0 and $11.5 \mathrm{~kg}$, which correspond to a ratio of $80 \%$ to $120 \%$ if the pregnancy is carried to term ( $40 \mathrm{wk})$. Therefore, a weight gain ratio $>1.20$ would be defined as gaining above the IOM recommendation (excessive) and those who have a ratio $<0.80$ would be defined as gaining below the IOM recommendation (inadequate) (Rasmussen \& Yaktine, 2009).

\section{Statistical Methods}

First, t-tests were conducted to examine the association between marginal food insecurity status and each of the candidate predictor variables for the continuous variables of income, age, number of children, physical activity (METS), dietary restraint, pregravid BMI, gestational weight gain, and observed to recommended weight gain ratio. Chi squared tests were conducted to examine the association between marginal food insecurity and dichotomous and categorical covariates of education, maternal race, marital status, and smoking status and with dietary restraint. Additive interaction between marginal food insecurity and high dietary restraint was tested using likelihood ratio test comparing an unrestricted model with the two main effects (marginal food insecurity and high dietary restraint) and the interaction term to the restricted model (without the interaction term) for the continuous outcomes. A Chi squared with a $\mathrm{p}$ value $\leq 0.15$ indicated the unrestricted model as a better fit suggesting the interaction term contributed to the model (Selvin, 1996). Significant interactions were found, therefore linear regression models stratified by low and high dietary restraint were used to estimate the association of marginal food insecurity on 
total gestational weight gain and weight gain ratio. A multinomial logistic regression was used to estimate the association between the two main effects and the interaction term and the three categories of weight gain: adequate, inadequate and excessive. To assess an interaction for the categorical outcome weight gain adequacy, especially since the excessive weight gain category is a prevalent outcome $(>60 \%)$, we estimated the relative excess risk due to the interaction (RERI) using a linear combination following Richardson \& Kaufman (Richardson \& Kaufman, 2009). To assess stability of the estimates, sensitivity analysis was conducted in three ways. First, from the 1,041 pregnant women who had completed the study and had complete information on weight gain, household food security status and dietary restraint, we limited the analysis to pregnant women from households with incomes at or below $400 \%$ of the federal income/poverty ratio $(n=477)$. The household income restriction allowed better comparison among households that might be food insecure due to financial and material constraints and purposefully excluded any households with higher incomes. Second, we tested for these interactions and the association excluding women who delivered preterm births $(\mathrm{n}=127,12.2 \%)$. Third, we also tested the interactions and estimated the associations for each of the dietary restraint sub-scales — dieting and cycling to identify if one dimension of the Revised Restraint Scale was driving the interaction with food insecurity and gestational weight gain. We estimated the linear combination of the main effects and the interaction term to interpret the interaction of marginal food insecurity and high dietary restraint, dieting and cycling.

Potential confounders included age (continuous), education (continuous), race (indicator for black as compared to white and other), income/poverty ratio (continuous), marital status (not married compared to married), number of children (continuous), any smoking during the first 6 months of pregnancy (dichotomous) and total metabolic equivalents hours per week of any physical activity (continuous) (Ainsworth et al., 2000; Ainsworth, Leon, Richardson, Jacobs, \& Paffenbarger, 1993). We did not control for dietary intake because this is a possible mediator between the exposures of food insecurity and dietary restraint and gestational weight gain. Pregravid BMI (continuous) and week gestation at the last weight measurement (continuous) were also retained as covariates. Stata software was used for data management and statistical calculations (StataCorp, 2007).

\section{RESULTS}

In this sample, $62.3 \%$ of pregnant women gained in excess of the IOM recommendations, while $12.6 \%$ gain inadequate weight and $25.1 \%$ gained adequate weight. Of the 1,041 pregnant women in this analysis, $128(12.3 \%)$ met the criteria for marginal food insecurity. Marginal food insecurity and dietary restraint were not significantly associated $\left(X^{2}=2.54\right.$, $\mathrm{p}<0.11)$.

Comparison of group means using a t-test showed that women exposed to marginal food insecurity and who scored high on dietary restraint had significantly higher gestational weight gain $(\mathrm{kg})$ and a higher observed to recommended weight gain ratio (See Table 1). A significant interaction was found between marginal food insecurity and scoring high on dietary restraint with regards to gestational weight gain (Likelihood Ratio (LR) $X^{2}=6.69, P$ $\leq 0.005)$ and weight gain ratio $\left(\mathrm{LR} X^{2}=7.92, \mathrm{P} \leq 0.005\right)$.

In adjusted models stratified by dietary restrain, women reporting low dietary restraint scores but who experienced marginal food insecurity had significantly lower total kilograms weight gain and a lower observed-to-recommended weight gain ratio compared to women reporting low dietary restraint score from food secure households, after adjusting for age, race, education, income, marital status, number of children, pregravid BMI, smoking, first trimester physical activity and gestational age at the last weight measure, (See Table 2). 
Significantly higher total kilograms of weight gain and a higher observed-to-recommended weight gain ratio were found among women reporting high dietary restraint scores and marginal food insecurity compared to women reporting higher dietary restraint score from food secure households. The results were remarkably similar in magnitude of association when the sample was restricted to income $\leq 400 \%$ income/poverty ratio, and restricted to only full-term deliveries, although the association between marginal food insecurity and observed-to-recommended weight gain ratio among women reporting low dietary restraint was no longer significant (See Table 2). The findings from the sensitivity analysis using the restricted samples suggest that the associations between marginal food insecurity stratified by dietary restraint and weight gain outcomes are stable estimates.

For the categorical weight gain outcome, the coefficient for the relative excess risk due to interaction (RERI) was 1.95 (95\% CI: 0.19, 3.71), which was a significant increase beyond the additive association of marginal food insecurity and high dietary restraint. The RERI was similar when we excluded preterm birth [1.78, 95\% CI: $0.12,3.44]$, but was less precise in the sensitivity analysis that was restricted to women with $\$ 400 \%$ income/poverty ratio [2.65, 95\% CI: $-0.40,5.70, \mathrm{p} \unlhd 5.09]$. We found no RERI with regard to inadequate weight gain.

Table 3 shows the results for the linear combination of marginal food insecurity, dietary restraint and the interaction for the full and restricted cohort ( $\$ 400 \%$ income/poverty ratio), as well as for each sub-scale. The results do not change for the restricted cohort. The estimates for linear combination of the interaction between marginal food insecurity and dietary restraint sub-scales were significant and had a similar magnitude of association as the full scale, suggesting that neither of the sub-scales is contributing more than the other to the association with increased weight gain.

\section{DISCUSSION}

Weight gain during pregnancy is often not within the targeted range, particularly in low income populations. In this sample of pregnant women only $25.5 \%$ gained adequate weight, while $62 \%$ gained excessive weight and another $12.5 \%$ gained inadequate weight according to the 2009 Institute of Medicine guidelines. We found that $12.3 \%$ of pregnant women were exposed to marginal food insecurity, a known predictor of weight gain during pregnancy. During the current economic downturn, household food insecurity increased from $12 \%$ in 2007 to $14.7 \%$ in 2008 and remained at 15\% in 2009 (Nord, Andrews, \& Carlson, 2008, 2009; Nord, Coleman-Jensen, Andrew, \& Carlson, 2010). Furthermore, these prevalence rates do not account for the number of people who are marginally food secure, and are worried about being able to feed their family or that food will run out.

We hypothesized that the combination of marginal food insecurity and high dietary restraint would lead to greater weight gain during pregnancy. Indeed, beginning pregnancy with exposure to marginal food insecurity as well as scoring high on restrained eating was associated with greater weight gain during pregnancy, both in total kilograms $(4.7 \mathrm{~kg})$ and as evidenced by a higher observed to recommended weight gain ratio. The findings for the interactive association between marginal food insecurity and restrained eating are almost twice those for food insecurity alone that we previously identified (Laraia et al., 2010). In fact, marginal food insecurity in the absence of high dietary restraint was significantly associated with lower kilograms of total weight gain and a lower observed-to-recommended weight gain ratio. For the categorical outcome of excessive or inadequate compared to adequate weight gain, we found a significant relative risk due to interaction for excessive weight gain but not for inadequate weight gain. The findings suggest that exposure to both marginal food insecurity and high dietary restraint has a synergistic relationship with regard 
to gaining outside of the IOM guidelines. Marginal food insecurity and dietary restraint may overlap to a certain extent, and it may be that past findings on food insecurity are due in large part to the combination of food insecurity and high dietary restraint. Similarly, findings for dietary restraint might be clarified by also looking at food insecurity. Conway et al. (1999), when just looking at dietary restraint, found it led to both gaining too much as well as gaining too little (Conway et al., 1999). It may be that in combination with food insecurity, this tips the balance toward gaining too much weight as the most frequent outcome.

It is unclear how the combination of marginal food insecurity and dietary restraint has effects on weight. Food insecurity alone has effects on eating behavior. Exposure to household food insecurity is hypothesized to cause weight gain because of financial resource constraints whereby a household becomes dependent on high calorie dense foods during periods of the month when resources are available, then restrict intake when resources fall short to meet household food needs (Dietz, 1995; Drewnowski \& Specter, 2004; Olson, 1999). When households can afford foods, they may choose high-energy dense foods not only because they are inexpensive, but also because they are highly palatable and more satiating. This pattern of eating high calorie dense foods at the beginning of the month followed by forced food restriction because of a lack of financial resources at the end of the month may mimic the yo-yo type diet, dieting followed by overeating, that could lead to weight gain. Once unwanted weight is gained, the potential for a cycle to diet and then food restrict starts. Women in this study who were from households characterized as marginally food insecure and who scored high on dietary restraint were of significantly lower income and education, and they also began with higher BMI levels. In combination with high levels of restraint, exposure to food insecurity may have led to greater psychological insecurity, feeling out of control, and more frequent or severe bouts of dysregulated eating. Fairburn \& Welch (1990) reported high levels of overeating and feeling out of control in pregnant women that was associated with excessive weight gain, especially among previous dieters, even without food insecurity (Fairburn \& Welch, 1990).

We must note that restraint is a complex construct, and our findings may not apply to all measures of restraint. The Revised Restraint Scale (RRS), used here, appears to be a proxy measure for the "unhealthy restraint", an all or nothing approach to eating (Westenhoefer, 1991), or emotional eating, preoccupation with food, and unrealistic expectations and strategies to restrict foods that are followed by overeating, which are associated with unsuccessful dieting and weight gain (Conway et al., 1999; Stice, Cameron, Killen, Hayward, \& Taylor, 1999; Stice, Hayward, Cameron, Killen, \& Taylor, 2000; Stice, Presnell, Shaw, \& Rohde, 2005). People who score high on self reported dietary restraint (when not part of a formal dieting program), particularly when measured by the Revised Restraint Scale (RRS), tend to gain weight over time (Stice et al., 1999; Stice et al., 2000; Stice et al., 2005). Future studies should distinguish between unhealthy restraint and more effective restraint strategies. Westenhoefer et al. (Westenhoefer, Broeckmann, Munch, \& Pudel, 1994) termed a more effect strategy as "flexible control" which includes allowance of limited sweets and planned compensation of increased food intake without feelings of guilt, and showed that flexible control was associated with reduced food intake following a preload of food, whereas participants with rigid restraint and disinhibition ate more.

Women from households characterized by marginal food insecurity and who have struggled with their weight will most likely continue to struggle with weight gain during pregnancy and gain more weight than their food secure counterparts. In addition to current weight status, self reports of dietary restraint and/or emotional eating may be the best predictors of weight gain during stressful events, which may include pregnancy. For example, people who identify as emotional eaters are more likely to gain weight in response to a naturalistic 
stressor or lab stressor (Epel et al., 2004; Van Strien, Frijters, Bergers, \& Defares, 1986), and to regain weight after a diet or surgical weight loss intervention (Larsen et al., 2006; Wing \& Phelan, 2005).

There are several limitations to the current study. For example, women who were excluded from this analysis because of missing data on pregravid height and weight, gestational weight gain, birth outcomes, household food security status or lacked information on the revised restraint scale had a lower mean age, mean education, mean income and a higher proportion were black. Therefore, the exclusion of these women may have biased the findings, possibly underestimating or overestimating the potential risk. The analysis of the association between self-reported dietary restraint and marginal food insecurity status for this study is cross-sectional and the observational nature of this study does not allow for causal relationships to be made, however, the temporal nature of gestational weight gain coming after the reporting of marginal food insecurity and dietary restraint suggests that these exposures may be antecedents for gestational weight gain. Further studies will need to be conducted on a representative sample of women from various ethnic backgrounds to confirm these findings. Furthermore, we hypothesized that the exposure of prior dietary restraint eating behavior and marginal household food insecurity happening before and during pregnancy would interfere with a woman's ability to meet the optimal gestational weight gain recommendation; however, we were not able to measure dietary restraint during pregnancy or estimate the total calories eaten on an average day. These additional measures would strengthen the findings by providing an indication of whether the interaction between marginal food insecurity and dietary restraint indeed led to a higher caloric intake. And finally, self-reported weight was used to calculate pregravid BMI. There are several studies that suggest self-report correlates well with actual weight, and all weights in this study were checked for biologic plausibility of the self-reported weight with the first prenatal visit measured weight if it occurred before 15 weeks and corrected it if deemed implausible. However, self-reported weight is problematic since the adequacy of gestational weight gain outcome variables were based on pregravid BMI. For example, a weight gain of 30 pounds would be adequate for a normal weight woman (weight gain recommendation is between 25-35 pounds) but would excessive for an overweight woman (weight gain recommendation is between 15-25 pounds). If an overweight woman underreported her pregravid weight to the extent that she was classified as being within the normal pregravid BMI category, the 30 pound weight gain would be classified as adequate biasing the findings to the null hypothesis of no association with marginal food insecurity status.

These findings underscore the importance of the emerging field examining the extent to which household food insecurity plays a large role in weight gain. Individual-level dietary restraint is clearly important, especially in the context of household food insecurity. Future studies should measure successful dietary restraint behaviors, those that prevent weight gain, in addition to "unhealthy" restraint behavior, as measured here.

\section{References}

Adam TC, Epel ES. Stress, eating and the reward system. Physiology \& Behavior. 2007; 91:449-458. [PubMed: 17543357]

Adams EJ, Grummer-Strawn L, Chavez G. Food insecurity is associated with increased risk of obesity in California women. Journal of Nutrition. 2003; 133:1070-1074. [PubMed: 12672921]

Ainsworth BE, Haskell WL, Whitt MC, Irwin ML, Swartz AM, Strath SJ, Leon AS. Compendium of Physical Activities: An update of activity codes and MET intensities. Medicine and Science in Sports and Exercise. 2000; 32:S498. [PubMed: 10993420] 
Ainsworth BE, Leon AS, Richardson MT, Jacobs DR, Paffenbarger RS Jr. Accuracy of the College Alumnus Physical Activity Questionnaire. Journal of Clinical Epidemiology. 1993; 46:1403-1411. [PubMed: 8263567]

Anderson SA. Core indicators of nutritional state for difficult-to-sample populations. Journal of Nutrition. 1990; 120(11S)

Bickel, G.; Nord, M.; Price, C.; Hamilton, W.; Cook, J. Guide to Measuring Household Food Security, Revised 2000. Alexandria, VA: USDA; 2000.

Casey P, Goolsby S, Berkowitz C, Frank D, Cook J, Cutts D, Meyers A. Maternal depression, changing public assistance, food security, and child health status. Pediatrics. 2004; 113:298-304. [PubMed: 14754941]

Che J, Chen J. Food insecurity in Canadian households. Health Reports. 2001; 12:11-22. [PubMed: 15069808]

Conway R, Reddy S, Davies J. Dietary restraint and weight gain during pregnancy. European Journal of Clinical Nutrition. 1999; 53:849-853. [PubMed: 10556996]

Deierlein AL, Siega-Riz AM, Herring A. Dietary energy density but not glycemic load is associated with gestational weight gain. American Journal of Clinical Nutrition. 2008; 88:693-699. [PubMed: 18779285]

Dietz WH. Does hunger cause obesity? Pediatrics. 1995; 95:766-767. [PubMed: 7724321]

Drewnowski A, Specter SE. Poverty and obesity: the role of energy density and energy costs. American Journal of Clinical Nutrition. 2004; 79:6-16. [PubMed: 14684391]

Epel ES, Blackburn EH, Lin J, Dhabhar FS, Adler NE, Morrow JD, Cawthon RM. Accelerated telomere shortening in response to life stress. Proceedings of the National Academies of Sciences U S A. 2004; 101:17312-17315.

Fairburn CG, Welch SL. The impact of pregnancy on eating habits and attitudes to shape and weight. International Journal of Eating Disorders. 1990; 9:153-160.

Gundersen C, Weinreb L, Wehler C, Hosmer D. Homelessness and food insecurity. Journal of Housing Economics. 2003; 12:250-272.

Hamelin AM, Beaudry M, Habicht JP. Characterization of household food insecurity in Quebec: food and feelings. Social Science \& Medicine. 2002; 54:119-132. [PubMed: 11820676]

Herman CP, Mack D. Restrained and unrestrained eating. Journal of Personality. 1975; 43:647-660. [PubMed: 1206453]

Herman, CPPJ., editor. Restrained Eating. Philadelphia: Saunders; 1980.

Hurley KM, Caulfield LE, Sacco LM, Costigan KA, Dipietro JA. Psychosocial influences in dietary patterns during pregnancy. Journal of the American Dietetic Association. 2005; 105:963-966. [PubMed: 15942549]

Jones SJ, Frongillo EA. Food insecurity and subsequent weight gain in women. Public Health Nutrition. 2007; 10:145-151. [PubMed: 17261223]

Kendall A, Olson CM, Frongillo ED. Relationship of hunger and food insecurity to food availability and consumption. Journal of the American Dietetic Association. 1996; 96:1019-1024. [PubMed: 8841164]

Kleinman RE, Murphy JM, Little M, Pagano M, Wehler CA, Regal K, Jellinek MS. Hunger in children in the United States: potential behavioral and emotional correlates. Pediatrics. 1998; 101:E3. [PubMed: 9417167]

Laraia B, Siega-Riz AM, Gundersen C. Household food insecurity is associated with self-reported pregravid weight status, gestational weight gain and pregnancy complications. Journal of the American Dietetic Association. 2010; 110:692-701. [PubMed: 20430130]

Laraia BA, Siega-Riz AM, Gundersen C, Dole N. Psychosocial factors and socioeconomic indicators are associated with household food insecurity among pregnant women. Journal of Nutrition. 2006; 136:177-182. [PubMed: 16365079]

Larsen JK, Geenen R, van Ramshorst B, Brand N, Hox JJ, Stroebe W, van Doornen LJ. Binge eating and exercise behavior after surgery for severe obesity: a structural equation model. International Journal of Eating Disorders. 2006; 39:369-375. [PubMed: 16528729] 
Mumford SL, Siega-Riz AM, Herring A, Evenson KR. Dietary restraint and gestational weight gain. Journal of the American Dietetic Association. 2008; 108:1646-1653. [PubMed: 18926129]

Nord, M.; Andrews, M.; Carlson, S. Household Food Security in the United States, 2007. Economic Research Report, ERR-66. 2008. Retrieved from http://www.ers.usda.gov/media/189485/err66.pdf

Nord, M.; Andrews, M.; Carlson, S. Household Food Security in the United States, 2008. Economic Research Support, ERR-83. 2009. Retrieved from http://www.ers.usda.gov/media/184956/ err83_1_.pdf

Nord, M.; Coleman-Jensen, A.; Andrew, M.; Carlson, S. Household Food Security in the United States, 2009. Economic Research Report, ERR-108. 2010. Retrieved from http:// www.ers.usda.gov/media/122550/err108_1_.pdf

Olson CM. Nutrition and health outcomes associated with food insecurity and hunger. Journal of Nutrition. 1999; 129:521S-524S. [PubMed: 10064322]

Rasmussen, KM.; Yaktine, AL., editors. Weight Gain During Pregnancy: Reexamining the Guidelines. Washington, DC: National Academies Press; 2009.

Richardson DB, Kaufman JS. Estimation of the relative excess risk due to interaction and associated confidence bounds. American Journal of Epidemiology. 2009; 169:756-760. [PubMed: 19211620]

Ruderman AJ. The restraint scale: a psychometric investigation. Behaviour Research and Therapy. 1983; 21:253-258. [PubMed: 6615391]

Seligman HK, Jacobs EA, Lopez A, Tschann J, Fernandez A. Food insecurity and glycemic control among low-income patients with type 2 diabetes. Diabetes Care. 2012; 35:233-238. [PubMed: 22210570]

Selvin, S. Statistical Analysis of Epidemiologic Data. New York, NY: Oxford University Press; 1996.

Siega-Riz AM, Adair LS, Hobel CJ. Institute of Medicine maternal weight gain recommendations and pregnancy outcome in a predominantly Hispanic population. Obstetrics \& Gynecology. 1994; 84:565-573. [PubMed: 8090394]

Siega-Riz AM, Adair LS, Hobel CJ. Maternal underweight status and inadequate rate of weight gain during the third trimester of pregnancy increases the risk of preterm delivery. Journal of Nutrition. 1996; 126:146-153. [PubMed: 8558295]

StataCorp. Stata Statistical Software: Release 10. College Station, TX: StataCorp LP; 2007.

Stevens-Simon C, Roghmann KJ, McAnarney ER. Relationship of self-reported prepregnant weight and weight gain during pregnancy to maternal body habitus and age. Journal of the American Dietetic Association. 1992; 92:85-87. [PubMed: 1728630]

Stice E, Cameron RP, Killen JD, Hayward C, Taylor CB. Naturalistic weight-reduction efforts prospectively predict growth in relative weight and onset of obesity among female adolescents. Journal of Consulting and Clinical Psychology. 1999; 67:967-974. [PubMed: 10596518]

Stice E, Hayward C, Cameron RP, Killen JD, Taylor CB. Body-image and eating disturbances predict onset of depression among female adolescents: a longitudinal study. Journal of Abnormal Psychology. 2000; 109:438-444. [PubMed: 11016113]

Stice E, Presnell K, Shaw H, Rohde P. Psychological and behavioral risk factors for obesity onset in adolescent girls: a prospective study. Journal of Consulting and Clinical Psychology. 2005; 73:195-202. [PubMed: 15796626]

Stuff JE, Casey PH, Szeto KL, Gossett JM, Robbins JM, Simpson PM, Bogle ML. Household food insecurity is associated with adult health status. Journal of Nutrition. 2004; 134:2330-2335. [PubMed: 15333724]

Taren DL, Clark W, Chernesky M, Quirk E. Weekly food servings and participation in social programs among low income families. American Journal of Public Health. 1990; 80:1376-1378. [PubMed: 2240310]

Townsend MS, Peerson J, Love B, Achterberg C, Murphy SP. Food insecurity is positively related to overweight in women. Journal of Nutrition. 2001; 131:1738-1745. [PubMed: 11385061]

Van Strien T, Frijters J, Bergers G, Defares P. The Dutch Eating Behavior Questionnaire (DEBQ) for assessment of restrained, emotional, and external eating behavior. International Journal of Eating Disorders. 1986; 5:295-315.

Vozoris NT, Tarasuk VS. Household food insufficiency is associated with poorer health. Journal of Nutrition. 2003; 133:120-126. [PubMed: 12514278] 
Westenhoefer J. Dietary restraint and disinhibition: is restraint a homogeneous construct? Appetite. 1991; 16:45-55. [PubMed: 2018403]

Westenhoefer J, Broeckmann P, Munch AK, Pudel V. Cognitive control of eating behaviour and the disinhibition effect. Appetite. 1994; 23:27-41. [PubMed: 7826055]

Wilde PE, Peterman JN. Individual weight change is associated with household food security status. Journal of Nutrition. 2006; 136:1395-1400. [PubMed: 16614436]

Wing RR, Phelan S. Long-term weight loss maintenance. American Journal of Clinical Nutrition. 2005; 82:222S-225S. [PubMed: 16002825]

Yu SM, Nagey DA. Validity of self-reported pregravid weight. Annals of Epidemiology. 1992; 2:715721. [PubMed: 1342323]

Ziliak, J.; Gundersen, C. Senior hunger in the United States: Differences across states and rural and urban areas. University of Kentucky Center for Poverty Research Special Reports. 2009. Retrieved [October 26, 2011] from http://www.mowaa.org/document.doc?id=193 


\section{Highlights}

- Food insecurity was previously associated with high gestational weight gain

- Dietary restraint is a measure of past failed dieting and weight fluctuation

- A significant interaction between marginal food insecurity and dietary restraint was found

- Pregnant women with marginal food insecurity and high dietary restraint gained more weight

- Pregnant women with marginal food insecurity and low dietary restraint gained less weight 


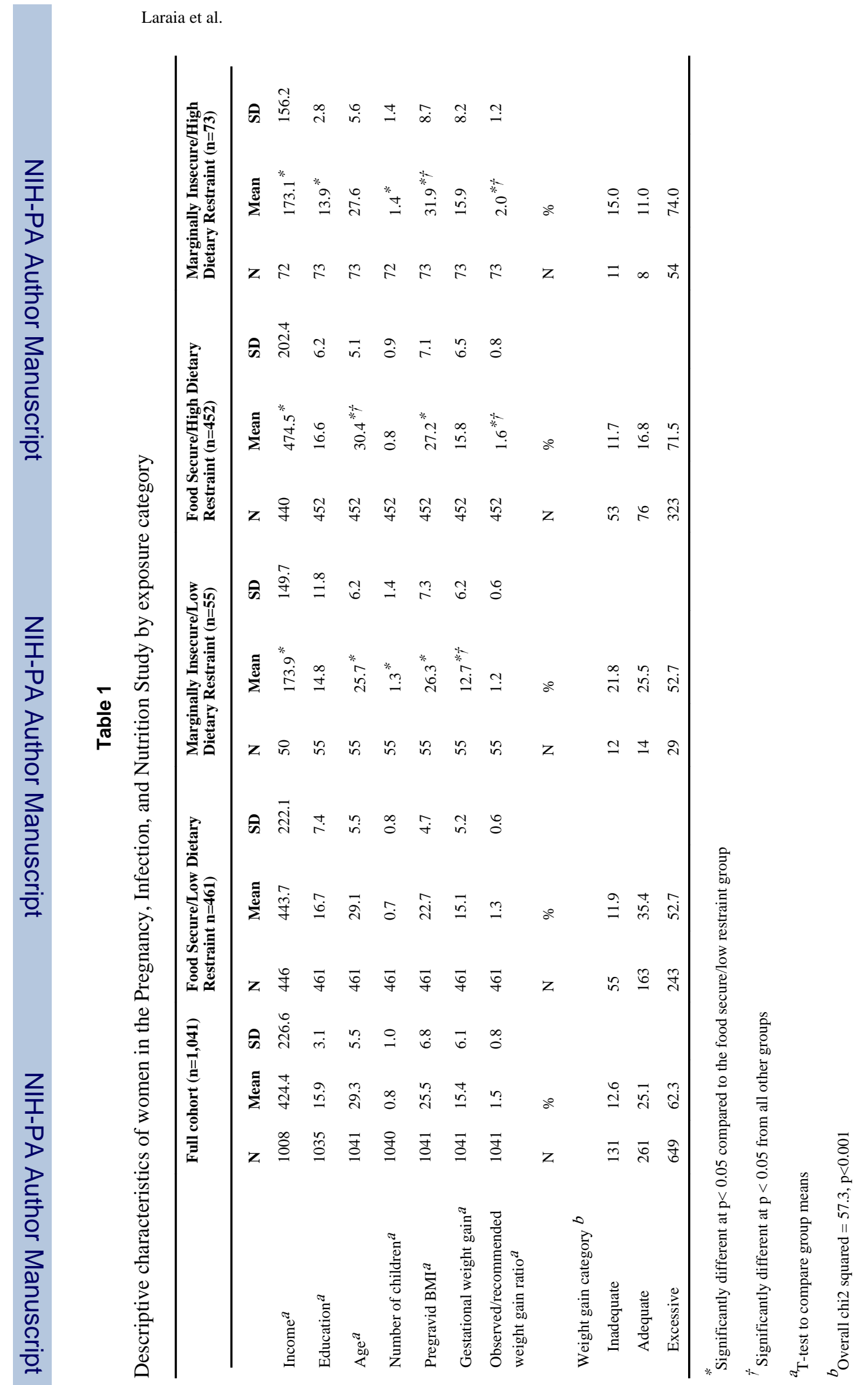




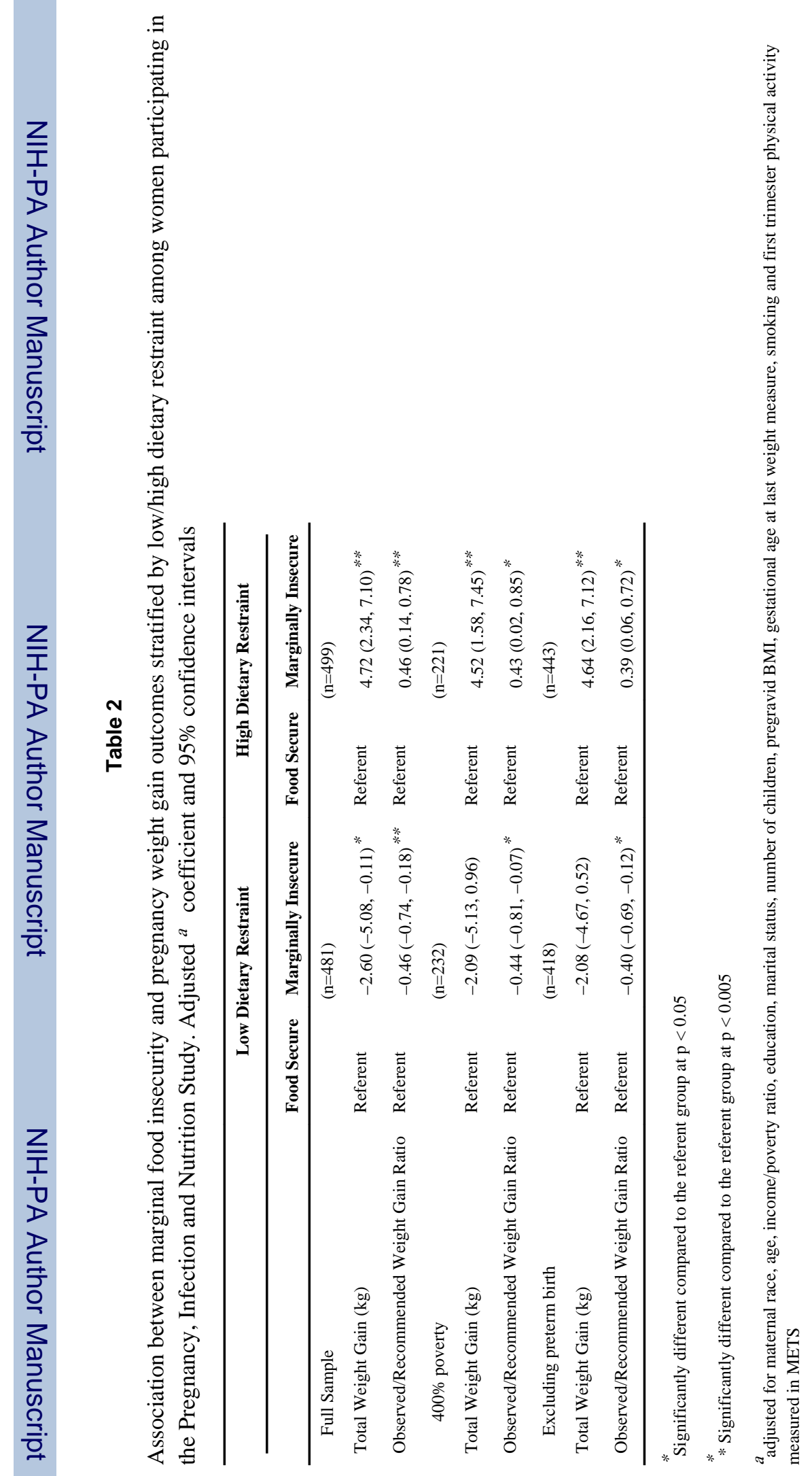

Appetite. Author manuscript; available in PMC 2014 June 01. 


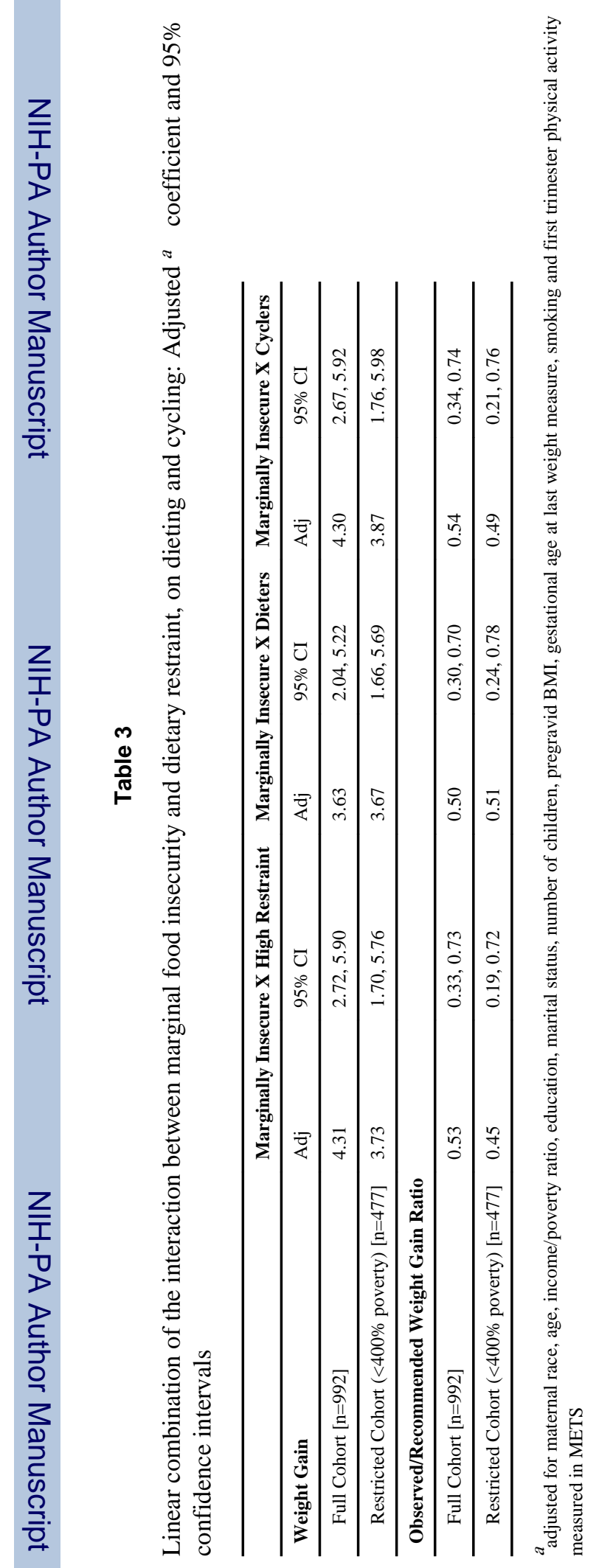

Appetite. Author manuscript; available in PMC 2014 June 01. 